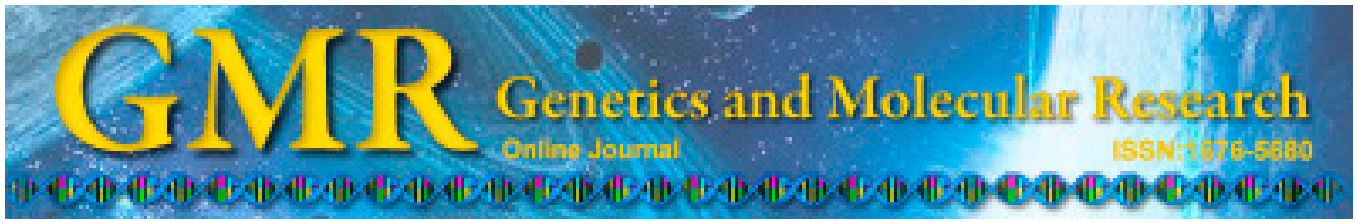

\title{
Population structure and genetic variation of the endangered species Elaeagnus mollis Diels (Elaeagnaceae)
}

\author{
J.M. Zhang ${ }^{1}$ and F. Zhang ${ }^{2,3}$ \\ ${ }^{1}$ Powerchina Guiyang Engineering Corporation, Guiyang, China \\ ${ }^{2}$ School of Life Science and Technology, Shanxi University, Taiyuan, China \\ Corresponding author: J.M. Zhang \\ E-mail: jminzhangen@163.com
}

Genet. Mol. Res. 14 (2): 5950-5957 (2015)

Received August 15, 2014

Accepted January 19, 2015

Published June 1, 2015

DOI http://dx.doi.org/10.4238/2015.June.1.12

\begin{abstract}
Elaeagnus mollis Diels is a group of shrubs and dwarf trees endemic to China and are endangered plants. However, the reason why these plants are endangered remains controversial. The current study aimed to explore the endangered status of E. mollis from a genetic perspective and to propose conservation strategies for this species. Using 16 polymorphic allozyme loci, the population genetic structure was investigated for three populations representing the taxa and variants. The variants exhibited relatively high levels of genetic variation compared to other woody shrubs with similar geographic distributions. The overall genetic diversity $\left(H_{\mathrm{E}}=0.352\right)$ was elevated compared to long-lived woody angiosperms. The average number of alleles per locus $(A)$, percentage polymorphic loci $(P)$, and observed heterozygosity $\left(H_{\mathrm{O}}\right)$ were $2.0,85.2$, and 0.371 , respectively. Furthermore, gene flow estimates within the population groups were also elevated. The life history and habitats of $E$. mollis play major roles in the levels of genetic diversity. The results of this study may help to device strategies for preserving the genetic diversity of E. mollis and
\end{abstract}


for promoting planting.

Key words: Elaeagnus mollis; Allozymes; Endangered species; Conservation; Population genetic structure

\section{INTRODUCTION}

Because rare species have a very uncertain fate, many studies have attempted to identify the features that characterize them (Young and Brown, 1996; Ge and Hong, 1999; Broadhurst and Coates, 2002).

Theoretically, species with limited ranges and few individuals will exhibit low levels of genetic polymorphism, and this phenomenon occurs because of selection under a narrow range of environmental conditions and genetic drift as well as inbreeding in small isolated populations (Ellstrand and Elam, 1993). Studies on genetic variation in plant species have revealed a strong association between the level of genetic diversity within a species and its geographic range (Hamrick and Godt, 1989). However, not all rare and endemic plant species are genetically depauperate, and some rare and endangered species maintain high levels of genetic variation (Young and Brown, 1996; Ge and Hong, 1999). Obviously, many other factors, such as life history traits, human activity, and evolutionary histories, may also influence the genetic variation and distribution of plant species (Karron et al., 1987).

Elaeagnus mollis Diels is a deciduous dwarf tree or shrub that is endemic to China. The species is a vestigial plant of the Quaternary Glaciation and is currently listed as endangered nationally (China State Environmental Protection Administration \& Institute of Botany Chinese Academy of Sciences, 1991). E. mollis is disjunctly distributed primarily in the hills and lower mountains of southern Shanxi (three populations) and at the northern foot of the Qinling Range

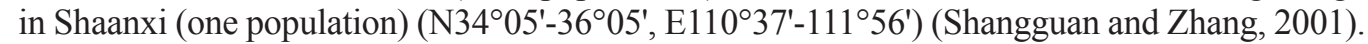
E. mollis is mainly pollinated by bees. The eco-environmental characteristics of E. mollis are typically efficient heat energy, little annual rainfall, and poor stands (Shangguan and Zhang, 2001; Zhang et al., 2001). Recent habitat fragmentation has affected all E. mollis populations by reducing their size and increasing their isolation (Qin et al., 2006, 2010).

To date, numerous researchers have investigated why E. mollis is endangered. The endangered status of $E$. mollis may not be related to low genetic diversity but instead to the specific breeding system of the species, as well as ecological factors (Qin et al., 2006, 2010; $\mathrm{Xu}$ et al., 2011). The endangered status of E. mollis may also be caused by strong artificial interference. A short seed life-span and low germination rate also endangers the species (Shangguan and Zhang, 2001). In addition, it is disadvantageous for seedlings and juvenile E. mollis to be in competition with other plants for various resources (Shangguan and Zhang, 2001). However, in these studies, the genetic diversity of $E$. mollis has been assessed using simple sequence repeat markers and randomly amplified polymorphic DNA, respectively. In conclusion, the definitive cause for the endangered status of the species remains controversial and further studies are required.

In this paper, for the first time, allozyme loci were used to examine E. mollis population genetics. Our objectives were to 1) determine the amount and distribution of genetic diversity within and between populations, 2) analyze the factors driving genetic diversity, and 3) provide recommendations for E. mollis conservation. 


\section{MATERIAL AND METHODS}

\section{Subjects}

E. mollis Diels (Elaeagnaceae) is a long-lived deciduous tree or shrub that grows to 2-10 $\mathrm{m}$ in height. The leaves alternate and are papyraceous, rarely membranaceous, ovate to ovate-elliptic, 6-15 cm long and 3-11 cm wide; the petioles are 6-15 $\mathrm{mm}$ long and semi-orbiculate. The flowers are hermaphroditic, grayish green, fragrant, and densely covered in stellate hairs; the pedicels are 3-4 mm long. Four stamens are present along with ellipsoid anthers approximately $1.6 \mathrm{~mm}$ long. The fruits are subglobose or broadly ellipsoid and approximately $13 \mathrm{~mm}$ long, with eight conspicuous raphes, wings, cottony sarcocarp. The flowering period is between April and May, and fruiting occurs between August and September.

\section{Areas investigated}

Most of the plants studied grew on a shady or half-shady slope at altitudes of 780-1,520 $\mathrm{m}$. The slopes were between $30^{\circ}$ and $60^{\circ}$. For low mountain areas, they primarily grew on slopes of $15-25^{\circ}$. The relative positions of the three populations studied were as follows: Xiangning population-Yicheng population, $78 \mathrm{~km}$; Yicheng population-Pinglu population, $108 \mathrm{~km}$; and Xiangning population-Pinglu population, $132 \mathrm{~km}$. The climate characteristics of the areas investigated are summarized in Table 1. The geographic locations of the areas studied are shown in Figure 1.

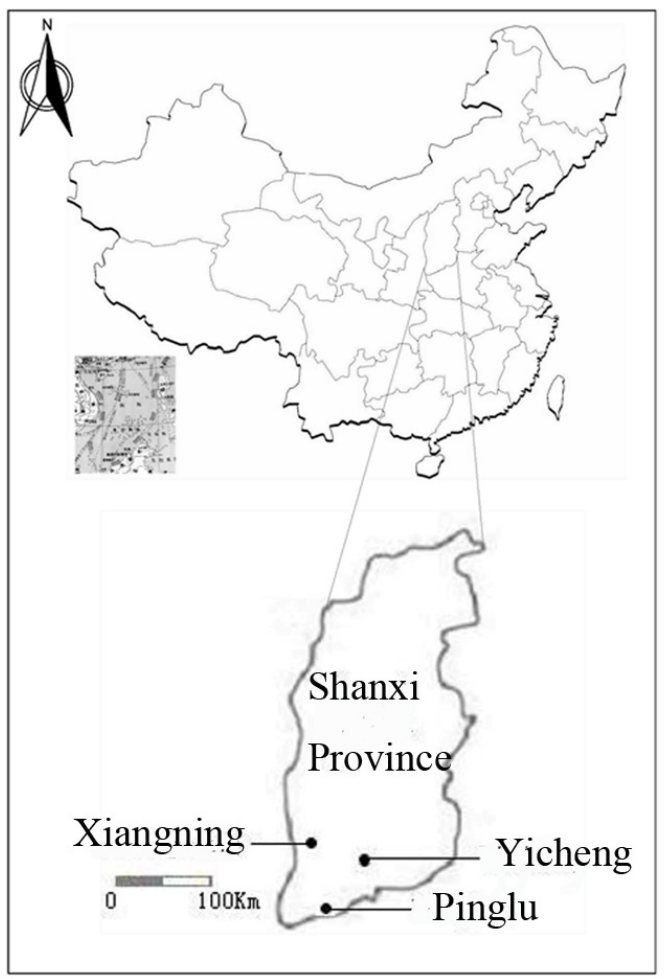

Figure 1. Locations of the study populations in Shanxi Province, China. 


Table 1. Climate characteristics of the study areas.
\begin{tabular}{lccc} 
& \\
\hline & Xiangning & Yicheng & Pinglu \\
\hline Average temperature $\left({ }^{\circ} \mathrm{C}\right)$ & 9.9 & 12.3 & 13.8 \\
Maximal temperature $\left({ }^{\circ} \mathrm{C}\right)$ & 35 & 41.3 & 41.3 \\
Minimal temperature $\left({ }^{\circ} \mathrm{C}\right)$ & -19.8 & -19.1 & -13.2 \\
Frost-free period $(\mathrm{d})$ & 212.6 & 547.8 & 238.4 \\
Average annual rainfall $(\mathrm{mm})$ & 570.2 & $1,200-1,340$ & 551.3 \\
Altitude $(\mathrm{m})$ & $1,200-1,520$ & & $920-1,060$ \\
\hline
\end{tabular}

\section{Sample collection}

Fresh leaves (without wormholes or corruption) were collected, sealed in plastic bags with wet filter paper, and were stored in a pot on ice. After returning from the field, samples were stored at $-20^{\circ} \mathrm{C}$. To avoid selecting samples from the same clone, the collection sites were located $20 \mathrm{~m}$ apart.

\section{Electrophoresis}

A total of 268 leaf samples were collected from three Shanxi populations (Figure 1). The leaves were stored at $-20^{\circ} \mathrm{C}$ for use in electrophoresis. Leaf tissues were ground in a chilled glass mortar with quartz powder. The fine powdered tissue was centrifuged for at 14,000 rpm for $30 \mathrm{~min}$ at $4{ }^{\circ} \mathrm{C}$, and the crude extract was mixed with an equal volume of $40 \%(\mathrm{w} / \mathrm{v})$ sucrose and 3-5 drops of $0.2 \%(\mathrm{w} / \mathrm{v})$ bromophenol blue. The solution extracted was divided into portions of $100 \mu \mathrm{l}$ per EP tube and stored at $-80^{\circ} \mathrm{C}$ until electrophoresis. This preparation and the isozyme methods were performed at the Institute of Loess Plateau, Shanxi University.

Allozyme diversity was determined via vertical slab polyacrylamide gel electrophoresis. The staining recipes for all enzymes have been previously described by Wang (1996) and were used with minor modifications. Individual gametophytes were smeared onto wicks that were pre-moistened with an extraction buffer-PVP solution. After the plant material was absorbed, the wicks were inserted into a vertical slit in the starch gel and subjected to horizontal electrophoresis at $4^{\circ} \mathrm{C}$. After the first 10-20 min of electrophoresis, the wicks were removed from the gel for better band definition. A spacer was routinely placed at the cathode end of the gel to slightly compress the gel and to insure that the slit did not open.

\section{Observation/measurement indices}

Fourteen enzyme systems were assayed (Wang, 1996): aspartate aminotransferase (AAT, E.C. 2.6.1.1), acid phosphatase (ACP, E.C. 3.1.3.2), esterase (EST, E.C. 3.1.1.-), peroxidase (PER, E.C. 1.11.1.-), alcohol dehydrogenase (ADH, E.C. 1.1.1.1), superoxide dismutase (SOD, E.C. 1.15.1.1), phosphogluconate dehydrogenase (PGD, E.C. 1.1.1.44), phosphoglucomutase (PGM, E.C. 5.4.2.2), glucose-6-phosphate isomerase (PGI, E.C. 5.3.1.9), formate dehydrogenase (FDH, E.C. 1.2.1.2), glucose-6-phosphate dehydrogenase (G-6-PD, E.C. 1.1.1.49), lactate dehydrogenase (LDH, E.C. 1.1.1.27), isocitrate dehydrogenase (IDH, E.C. 1.1.1.41), and malate dehydrogenase (MDH, E.C. 1.1.1.37). Eighteen putative allozyme zones of activity were clearly resolved, and sixteen polymorphic loci were detected. 
Standard measures of genetic diversity, including the average number of alleles per locus (A), percentage polymorphic loci $(\mathrm{P})$, observed heterozygosity $\left(H_{\mathrm{O}}\right)$, and gene diversity $\left(H_{\mathrm{E}}\right)$, were calculated for each population and across the populations. Wright's fixation index $(F)$, or the inbreeding coefficient measured deviation from Hardy-Weinberg (H-W) expectations.

\section{Statistical analysis}

The distribution of genetic variation within and between populations was calculated using Nei's gene diversity statistics. Interpopulation divergence was estimated using Nei's (1978) unbiased genetic distance $(D)$, Nei's unbiased genetic identity $(I)$, and the Modified Rogers distance $(D T)$ (Wright, 1978). Unweighted Pair Group Method with Arithmetic Mean (UPGMA) cluster analyses of $D, I$, and $D T$ examined the genetic associations between populations. The parameters above were determined using the BIOSYS-2 computer program (Swofford and Selander, 1997; Urbana, IL, USA).

An indirect estimate of gene flow $\left(N_{\mathrm{m}}\right)$ was calculated for all populations and within the two population groups based on the relationship $F_{\mathrm{ST}}=1 /\left(4 N_{\mathrm{m}}+1\right)$ (Wright 1978).

\section{RESULTS}

Among the fourteen assayed enzyme systems, two loci ( $A c p-2$ and $L d h)$ were monomorphic, and sixteen putative loci (Per-1, Per-2, Est-2, Est-3, Aat-1, Pgi-1, Pgm, Pgd-2, Sod-1, $M d h-1, M d h-3, G-6-p d-1, A d h-1, A d h-2, F d h$, and $I d h)$ were polymorphic across all populations.

The mean (Table 2) for all population estimates, including $\mathrm{P}=85.2, A=2.0, H_{\mathrm{O}}$ $=0.371$, and $H_{\mathrm{E}}=0.352$, revealed relatively high levels of genetic diversity for an animalpollinated outcrossed species (Hamrick and Godt, 1989). $F$ deviated from zero in all three populations, and there was generally more heterozygosity than expected based on geographical distribution and compared with other woody plant species with similar life histories. No significant departures from the $\mathrm{H}-\mathrm{W}$ equilibrium were detected. Of the total genetic diversity observed in the Shanxi population, approximately $85.35 \%$ was between populations, and $14.65 \%$ was within populations (Table 3 ).

Table 2. Estimates of genetic variability in Elaeagnus mollis based on 16 variable loci in three populations.

\begin{tabular}{lccccc}
\hline Population & $\mathrm{A}$ & $\mathrm{P} *$ & $H_{\mathrm{O}}$ & $H_{\mathrm{E}}^{* *}$ & \multicolumn{1}{c}{${ }^{*}$} \\
\hline Xiangning & $2.0(0.1)$ & 88.9 & $0.375(0.042)$ & $0.367(0.037)$ & -0.033 \\
Yicheng & $2.1(0.2)$ & 88.9 & $0.370(0.040)$ & $0.363(0.037)$ & -0.035 \\
Pinglu & $1.9(0.1)$ & 77.8 & $0.367(0.063)$ & $0.325(0.048)$ & -0.094 \\
Mean & 2.0 & 85.2 & 0.371 & 0.352 & -0.054 \\
\hline
\end{tabular}

*A locus is considered polymorphic if more than one allele is detected. **Expected heterozygosities are unbiased estimates (Nei, 1978). A = mean number of alleles per locus; $\mathrm{P}=$ percentage of polymorphic loci; $H_{\mathrm{O}}=$ observed heterozygosity averaged over all loci; $H_{\mathrm{E}}=\mathrm{H}-\mathrm{W}$ expected heterozygosity (unbiased); and $F=$ Wright's fixation index. Standard error is in parentheses.

Nei's unbiased genetic identity $(I)$ values were generally elevated and ranged from 0.786 to 1.000 , with a mean of 0.861 . The values of Nei's unbiased genetic distance $(D)$ were significantly reduced, and the mean was 0.156 . The phenogram produced with UPGMA cluster analysis depicted a close genetic relationship between the Xiangning and Yicheng populations. The same result was observed when the phenogram was produced according to $I, D$, or $D T$. 


\begin{tabular}{lccc}
\multicolumn{4}{c}{ Table 3. Summary of $F$-statistics at all loci in Shanxi Elaeagnus mollis. } \\
\hline Locus & $F_{\text {IS }}$ & $F_{\text {ST }}$ & $F_{\text {IT }}$ \\
\hline Per-1 & 0.0729 & 0.0743 & 0.1418 \\
Per-2 & 0.0391 & 0.2000 & 0.2313 \\
Est -2 & -0.1387 & 0.0046 & -0.1335 \\
Est -3 & 0.0301 & 0.0055 & 0.0355 \\
Aat -1 & -0.1262 & 0.0001 & -0.1261 \\
Pgi-1 & -0.2344 & 0.0885 & -0.1252 \\
Pgm & -0.2649 & 0.0055 & -0.2579 \\
Pgd-2 & -0.0250 & 0.0382 & 0.0142 \\
Sod-1 & -0.1862 & 0.4674 & 0.3683 \\
Mdh-1 & -0.1055 & 0.0370 & -0.0646 \\
Mdh-3 & -0.1766 & 0.1315 & -0.0219 \\
G-6-pd-1 & -0.1226 & 0.4120 & 0.3399 \\
Adh-1 & -0.0700 & 0.3357 & 0.2891 \\
Adh-2 & -0.1514 & 0.3346 & 0.2338 \\
Fdh & 0.3085 & 0.1554 & 0.4159 \\
Idh & 0.2286 & 0.0016 & 0.2299 \\
Mean & -0.0591 & 0.1465 & 0.0961 \\
\hline
\end{tabular}

Gene flow estimates within population groups were elevated even though the minimum geographical distance between any population pair was $78 \mathrm{~km}$ in the southern Shanxi Province. The overall estimated gene flow level between the populations was also elevated $\left(N_{\mathrm{m}}=2.2\right)$.

\section{DISCUSSION}

The level of genetic diversity observed in E. mollis $\left(H_{\mathrm{E}}=0.352\right)$ was considerably higher than that expected of long-lived woody angiosperms $\left(H_{\mathrm{E}}=0.183, \mathrm{se}=0.011\right)$ (Hamrick et al., 1992). The levels of diversity were more than five-fold the levels exhibited by other endemic taxa on a worldwide basis $\left(H_{\mathrm{E}}=0.078, \mathrm{SE}=0.016\right)$. Compared with 26 long-lived woody endemics $\left(P=0.263, \mathrm{SE}=0.039 ; A=1.48, \mathrm{SE}=0.09 ;\right.$ and $\left.H_{\mathrm{E}}=0.056, \mathrm{SE}=0.010\right)$ and 61 such species with narrow geographic distributions $(P=0.443, \mathrm{SE}=0.028 ; A=1.61, \mathrm{SE}$ $=0.05$; and $H_{\mathrm{E}}=0.143, \mathrm{SE}=0.010$ ) (Hamrick et al., 1992), E. mollis exhibited high genetic variability. These results suggest that $E$. mollis is not genetically depauperate.

Hamrick et al. (1992) found that species with narrow geographic distributions show low levels of genetic diversity $\left(H_{\mathrm{E}}=0.143, \mathrm{SE}=0.010\right)$. However, E. mollis is not the only rare species with high genetic diversity. Young and Brown (1996) observed high genetic diversity among populations of the rare woodland shrub Daviesia suaveolens. Furthermore, Ge and Hong (1999) proposed that the high diversity of the rare and endangered species Adenophora lobophylla resulted from ecological factors and life history.

Although $E$. mollis is a rare and endangered species, high genetic diversity among $E$. mollis populations was observed. There are several possible explanations. 1) E. mollis populations are generally large and are not subject to a significant loss of variation through smallpopulation effects, such as random genetic drift and inbreeding coupled with selection. 2) $E$. mollis is a long-lived species (Wang et al., 1992). This longevity supports the general findings of Hamrick and Godt (1989) that genetic variance will decay more slowly in long-lived species, and that populations will be less susceptible to drift. 3) E. mollis survived the Quaternary Glaciation. In addition, E. mollis has a high rate of root turion formation, which helps in maintaining the genetic diversity of their populations. 
The overall estimated level of gene flow between all populations was elevated $\left(N_{\mathrm{m}}=\right.$ 2.2). Generally, gene flow between populations of the same species is possible and can prevent local differentiation (Slatkin, 1987), and our study supports this assumption.

Compared with other endangered or rare species with high genetic diversity, conservative actions that suit local species were used, e.g., conservation measures for Nouelia insignis involved expanding the population range and enlarging the population size. Furthermore, introducing foreign germplasms to enhance the genetic diversity of this population may also be a viable option to protect this species (Luan et al., 2006). For Eryngium alpinium, conservation measures should preserve a maximum number of plants, with priority given to those individuals that are genetically most diverse and/or differentiated (Gaudeul et al., 2000). For Olea europaea, the vegetative propagation of existing individuals in different massifs or the production of novel plants stemming from seed germination has been proposed (Baali-Cherif and Besnard, 2005).

Although E. mollis is endangered and rare, it is not noticeably genetically depauperate. Based on these results, conservation strategies for E. mollis are recommended. Because of high gene flow, the possibility of local population adaptations is less likely compared with many other taxa. Reintroductions using seeds and seedlings from any convenient seed and seedling source may be feasible; however, a careful choice of seed source to match the reintroduction site according to proximity, soil type, or associated vegetation may not be necessary. Human activity, such as deforestation, has caused habitat destruction. Therefore, mixing seeds from different sources appears unlikely to jeopardize reintroduction efforts. Finally, a nature reserve should be established to protect $E$. mollis from human activity. We propose that future studies should focus on the evolutionary history of E. mollis to elucidate the causes of its endangered status.

\section{Conflicts of interest}

The authors declare no conflict of interest.

\section{ACKNOWLEDGMENTS}

Research supported by the Guizhou Science and Technology Foundation [project \#(2011)2363]. The authors thank Prof. J.M. Yuan and Prof. B.F. Chai for the use of their laboratory and the anonymous reviewers for their constructive comments on our manuscript.

\section{REFERENCES}

Baali-Cherif D and Besnard G (2005). High genetic diversity and clonal growth in relict populations of Olea europaea subsp. laperrinei (Oleaceae) from Hoggar, Algeria. Ann. Bot. 96: 823-830.

Broadhurst L and Coates D (2002). Genetic diversity within and divergence between rare and geographically widespread taxa of the Acacia acuminata Benth (Mimosaceae) complex. Heredity 88: 250-257.

China State Environmental Protection Administration \& Institute of Botany Chinese Academy of Sciences (1991). Rare or endangered Chinese plants. Science Press, Beijing.

Ellstrand NC and Elam DR (1993). Population genetic consequences of small population size: implications for plant conservation. Annu. Rev. Ecol. Sys. 23: 237-261.

Gaudeul M, Taberlet P and Till-bottraud I (2000). Genetic diversity in an endangered alpine plant, Eryngium alpinum L. (Apiaceae), inferred from amplified fragment length polymorphism markers. Mol. Ecol. 9: 1625-1637. 
Ge S and Hong DY (1999). Studies of morphological and allozyme variation of the endangered Adenophora lobophylla and its widespread congener A. potaninil. Acta Genet. Sin. 26: 410-417.

Hamrick JL and Godt MJW (1989). Allozyme Diversity in Plant Species. In: Plant Population Genetics, Breeding, and Genetic Resources (Brown HD, Clegg MT, Kahler AL and Weir BS, eds.). Sinauer Associates Inc., Sunderland, MA, 43-63.

Hamrick JL, Godt MJW and Sherman-Broyles SL (1992). Factors influencing levels of genetic diversity in woody plant species. New Forest 6: 95-124.

Karron JD (1987). A comparison of levels of genetic polymorphism and self-compatibility in geographically restricted and widespread plant congeners. Evol. Ecol. 1: 47-58.

Luan SS, Chiang TY and Gong X (2006). High genetic diversity vs low genetic differentiation in Nouelia insignis (Asteraceae), a narrowly distributed and endemic species in China, revealed by ISSR fingerprinting. Ann. Bot. 98: 583-589.

Nei M (1978). Estimation of average heterozygosity and genetic distance from a small number of individuals. Genetics 83: 583-590.

Qin YY, Zhang QD and Yan GQ (2006). RAPD analysis of genetic diversity in populations of the endangered plant of Elaeagnus mollis Diels. Mol. Plant Breed. 6: 31-36.

Qin YY, Wang YL, Zhang QD, Bi RC and Yan GQ (2010). Analysis on the population genetic diversity of an endangered plant (Elaeagnus mollis) by SSR markers. J. Wuhan Bot. Res. 28: 466-472.

Shangguan TL and Zhang F (2001). The endangered cases of Elaeagnus mollis an endemic to China. Acta Ecol. Sin. 21: $502-505$.

Slatkin M (1987). Gene flow and the geographic structure of natural populations. Science 236: 787-792

Swofford DL and Selander RB (1997). BIOSYS-2: A Computer Program for the Analysis of Allelic Variation in Genetics. University of Illinois, Urbana, Illinois, USA.

Wang ZR (1996). Analysis of plant allozyme. Science Press, Beijing, 87-90, 95-102, 112-118, 145-163.

Wang GX, Liu XQ and Qiao J (1992). Shanxi Forest. China Forestry Press, Beijing, 309-314

Wright S (1978). Variability Within and Among Natural Populations. In: Evolution and the Genetics of Populations, University of Chicago Press, Chicago, 79-103.

$\mathrm{Xu}$ Y, Lu P and Bi RC (2011). Studies on species characteristics and diversities of Elaeagnus mollis community in Shanxi. J. Shanxi Normal Univ. 25: 95-99.

Young AG and Brown AHD (1996). Comparative population genetic structure of the rare woodland shrub Daviesia suaveolens and its common congener D. mimosoides. Conser. Biol. 10: 1220-1228.

Zhang F, Han SQ and Shangguan TL (2001). Analysis on relationship between geographic distribution of Elaeagnus mollis and eco-environment factors in China. J. Shanxi Univ. 24: 86-88. 